\title{
CUADERNOS AUDIOVISUALES DE LABORATORIO: HACIA UNA MEJORA EN LA ENSEÑANZA DE LA QUÍMICA*
}

\author{
Seminario Permanente de Física y Química «Vegas Altas del Guadiana». \\ Instituto de Bachillerato Luis Chamizo. Carretera Don Benito-Villanueva \\ 06400 Don Benito (Badajoz).
}

* Este trabajo ha sido parcialmente subvencionado por el MEC-Junta de Extremadura.

\section{SUMMARY}

The Audiovisual Laboratory Notebooks are framed into the so-called «active methods for Chemistry teaching», and try to achieve an effective learning, more accurate and at the same time more agreable of the techniques and usual operations in the laboratory, and also a positive attitude towards Chemistry.

\section{INTRODUCCIÓN}

La enseñanza tradicional por transmisión oral de conocimientos donde los únicos materiales didácticos son los textos y la pizarra dio paso durante la década de los 60. 70 a los grandes proyectos curriculares de «aprendizaje por descubrimiento inductivo" (PSSC, BSCS, CBA, CHEM, Nuffield, etc.), cuya evaluación merece este juicio negativo de Ausubel (1978): «En realidad, con este procedimiento, los alumnos aprendieron poco de la materia y menos aún del método científico.»

Estas dos tendencias continúan en la actualidad en la enseñanza de la Química, aunque han sido seriamente discutidas por Gil (1983, 1986) o Hodson (1985). Este hecho representa una prueba más de que la investigación didáctica influye lenta y tardíamente en el desarrollo de los currículos de Ciencias.

Nuestro Seminario Permanente, con el «Método Activo de Química» (Seminario Permanente 1987), ha optado por una tercera vía, donde intentamos compaginar la teoría y la práctica de la Química en el marco del cambio conceptual y metodológico propuesto por Gil y Carrascosa (1985) con el objeto de conseguir la formación y participación del alumno más que la información como mero receptor, así como alcanzar un aprendizaje significativo y no anecdótico.

Por otra parte, un problema generalizado de las Ciencias Experimentales es la falta de interés y la actitud negativa creciente por parte del alumno. En un reciente trabajo (Yager y Penick 1986) se constata que «cuantos más años de Ciencias cursan nuestros alumnos menos les gustam. Este cambio en Ias actitudes de los alumnos en el período escolar ha sido investigado por numerosos autores, entre los que podemos destacar a Klopfer (1976), Giordan (1982), Hadden y col. (1982,1983), Mager (1985), Schibeci (1986), Serrano (1986, 1988) y Solbes (1989), lo que nos da idea de la fecundidad de esta línea de investigación.

Teniendo en cuenta los argumentos anteriores y para completar nuestro «Método Activo en Química», hemos introducido los medios audiovisuales, concretamente el vídeo didáctico de laboratorio, pues es reconocido el gran poder motivador de este medio. Con ello intentamos un cambio en la actitud de nuestros alumnos hacia la Ciencia, así como un cambio metodológico en la enseñanza de la Química, pues estamos de acuerdo con Gil y col. (Gené y Gil 1983, Gil y Payá 1984) sobre el hecho de que superar el inductivismo no estriba simplemente en modificar las prácticas de laboratorio, aunque ello sea absolutamente necesario (Gil 1986).

\section{MÉTODO}

Numerosos autores (Barnard et col. 1968, Duffy 1969, Nienhouse y Nash 1971, Garland 1971, Wetmore y Miller 1971, Mulder 1984, Martínez Aznar et al. 1987) han puesto de manifiesto que la aplicación más efectiva de la utilización de la televisión ha sido en la enseñanza de laboratorio. Así, ias técnicas de laboratorio, manejo de 
instrumentos o procedimientos para la manipulación de muestras son ideales para ser mostradas en TV (Nien. house y Nash 1971).

Las grandes ventajas del vídeo de laboratorio podemos resumirias diciendo que: proporcionan al alumno el conocimiento de la técnica que más tarde realizará en el laboratorio; disminuye en los problemas derivados de la manipulación defectuosa, lecturas incorrectas y repeticiones innecesarias; permiten acceder a un mayor número de alumnos de forma directa; permiten adquirir una información científica y técnica basada en la imagen -tremendamente sugestiva para la juventud-; $y$, finalmente, permiten considerar con facilidad la relevancia de otros aspectos, como Historia de la Ciencia o relación Ciencia/Técnica/Sociedad.

Así como se ha realizado un gran esfuerzo en la elaboración de material informático (software) para la enseñanza de las Ciencias Experimentales (para una revisión reciente ver A. Bautista 1987 ), no ocurre lo mismo en cuanto a la elaboración de vídeos didácticos que estén estrechamente relacionados con la realidad educativa española actual -recogida en el modelo de Reforma de las Enseñanzas Medias-, pues en la mayoría de los casos se trata de vídeos realizados por equipos extranjeros, de un altísimo nivel de producción, pero poco adaptados a Ia realidad diaria de nuestras aulas, y cuya traducción, a veces literal, no es fácilmente comprensible para nuestros alumnos.

En esta línea, durante el curso 1989-90 comenzamos Ia elaboración de una serie de vídeos didácticos sobre el laboratorio de Química, que hemos denominado cuadernos audiovisuales de laboratorio, ya que su uso debe insertarse en un método activo para la enseñanza de la Química $y$, por tanto, no puede concebirse como material aislado.

En su faceta operativa, cada vídeo ha sido realizado siguiendo las pautas comunes en la elaboración de material filmado, intentando compaginar el rigor científico, la amenidad y el contacto con la realidad, y tratando de huir en lo posible de una actitud dirigista por simple aplicación de recetas (Charen 1970). Como elemento de motivación y atención hemos incorporado unas secuencias de animación totalmente originales.

En la actualidad hemos preparado cuatro vídeos: «Mate* rial de Laboratorio. Operaciones Básicas. I y II», «Disoluciones» y «Ácidos y bases». Cada vídeo va acompañado de la correspondiente guía didáctica para el profesor.

\section{UTILIZACIÓN EN EL AULA YEVALUACIÓN}

Como hemos indicado antes, estos Cuadernos Audiovisuales de Laboratorio no pueden concebirse como material aislado, sino enmarcado en los métodos activos de Química, y los hemos planteado como un material internivelar, de tal manera que, debidamente programado, se pueda usar desde el último ciclo de EGB hasta el actual COU, o lo que sería la Enseñanza Secundaria Postobligatoria.

De acuerdo con la metodología activa de la Química que proponemos, la máxima eficacia se alcanzará si en una primera fase pasamos la cinta en clase; en una segunda fase, los alumnos contestan las cuestiones que se plantean en la guía didáctica o aquéllas que el profesor estime oportunas. La importancia de estas dos fases es crucial, pues el alumno toma contacto con la realidad a través de la imagen y comienza a plantearse cuestiones que más tarde deberá resolver experimentalmente. Estas dos primeras fases pueden repetirse tantas veces como sea necesario, total o parcialmente, lo que justifica el nombre de «Cuadernos» dado a esta serie. En una tercera fase, la realización práctica en el laboratorio completará las ideas de los alumnos, evitando errores innecesarios.

Como primera evaluación, hemos pasado la cinta «Di* soluciones» a un grupo de 23 profesores de EGB ajenos a este Seminario, en el curso «Técnicas de Laboratorio» impartido por nosotros, en la que tras el visionado se les ha pasado la encuesta que aparece en Ia tabla I. Los resultados aparecen también en la misma tabla.

Tabla I

\begin{tabular}{|c|c|c|c|c|c|}
\hline Cuestión & Mucho & Bastante & Normal & Poco & Nada \\
\hline 1. Me ha motivado al estudio del tema & 3 & 9 & 9 & 2 & 0 \\
\hline $\begin{array}{l}\text { 2. Me ha ayudado a descubrir aspectos complementarios } \\
\text { de un tema ya estudiado }\end{array}$ & 1 & 16 & 5 & 1 & 0 \\
\hline $\begin{array}{l}\text { 3. Me ha parecido un material autosuficiente para } \\
\text { comprender el tema }\end{array}$ & 1 & 10 & 9 & 2 & 1 \\
\hline $\begin{array}{l}\text { 4. Me ha servido para sustituir, en parte al menos, } \\
\text { aspectos prácticos del contenido didactico transmitido }\end{array}$ & 4 & 15 & 3 & 1 & 0 \\
\hline 5. Claridad & 5 & 14 & 4 & 0 & 0 \\
\hline 6. Estructuración & 2 & 10 & 10 & 1 & 0 \\
\hline 7. Interés & 4 & 11 & 7 & 1 & 0 \\
\hline 8. Profundidad & 1 & 9 & 10 & 3 & 0 \\
\hline 9. Calidad de imagen & 7 & 10 & 5 & I & 0 \\
\hline 10. Calidad de sonido & 7 & 8 & 7 & 1 & 0 \\
\hline
\end{tabular}


Aunque la muestra no es representativa, queremos indicar que se trata de una primera evaluación antes de proceder a la evaluación con alumnos. No obstante, estos resultados son bastante alentadores, pues nos dan una idea del grado de aceptación y responden a los objetivos que nos habíamos planteado, consiguiendo un aprendizaje experimental de la Química (cuestiones 2, 3, 6 y 8 ), además de una motivación (cuestiones 1 y 7 ). A pesar de los medios rudimentarios con los que hemos contado, se ha conseguido un producto de cierta calidad para ser expuesto (cuestiones 5,9 y 10 ).

Por otra parte, el próximo curso evaluaremos cada práctica con grupos de alumnos, pasando un test teórico-

\section{REFERENCIAS BIBLIOGRÁFICAS}

AUSUBEL, D. P., 1978. Psicología Educativa. Un punto de vista cognitivo. (Ed. Trillas: México).

BARNARD, W. R., BERTAUT, E.F. y O' CONNOR, R., 1968. J. Chem. Ed., 45 , p. 617.

BAUTISTA, A., 1987. Enseñanza de las Ciencias, 5(3), p. 255.

CHAREN, G., 1970. Sci, Ed., 54, pp. 267-271.

DUFFY, N. V., 1969. J. Chem. Ed., 46, p. 392.

GARLAND, J. K., 1971. J. Chem. Ed., 48, p. 207.

GENE, A. y GIL, D., 1983. Els treballs pràctics de Biologia el mètode científic. Una proposta basada en el descobriment guiat, pp. 135-149. Jornades de Recerca Educativa. Lleida, 1982 (ICE Universitat Autònoma de Barcelona).

GIL PÉREZ, D., 1983. Tres paradigmas básicos en la Enseñanza de las Ciencias, Enseñanza de las Ciencias, 1(1), pp. 26-33.

GIL PEREZ, D., 1986. La metodología científica y la enseñanza de las Ciencias. Unas relaciones controvertidas, Enseñanza de las Ciencias, 4 (2), pp. I11-121.

GIL PÉREZ, D. y CARRASCOSA, J., 1985. Science learning as a conceptual and methodological change, Eur. J. Sc. Ed., $7(3)$, pp. $231-236$.

GIL PÉREZ, D. y PAYȦ, J., 1984. Los trabajos prácticos de Física y Química y la metodología científica. XX Reunión Bienal de la Real Sociedad Española de Química. Castelión.

GIORDAN, A., 1982. Liberación. Prioridad de la actitud científica. La Enseñanza de las Ciencias, Pablo del Río, pp. 57-111, (S. XXI: Madrid).

HADDEN, R, y JOHNSTON, A., 1982. Primary School pupils' attitudes to Science: The year of formation, Eur. J. Sci. Education, 4(1), pp. 397-407.

HADDEN, R. y JOHNSTON, A., 1983. Secondary School pupils' attitudes to Science: The year of erosion, Eur. J.Sci. Education, 5(3), pp. 309-318. práctico al terminar las prácticas al cabo de un mes y al cabo de tres meses, con el objeto de determinar el grado de asimilación de los conceptos empleados. En todos los casos se tomarán grupos de control que sirvan para contrastar la experiencia.

\section{AGRADECIMIENTOS}

Deseamos expresar nuestro agradecimiento al profesor Federico Martinez Montero, coordinador del Proyecto Mercurio de la zona, por la ayuda técnica recibida y al profesor Segismundo Piédrola Galván por el trabajo de animación.

HADDEN, R. y JOHNSTON, A., 1983. Secondary School pupils attitudes to Science: The year of decision, Eur. J. Sci Education, S(4), pp. 429-438.

HODSON, D., 1985. Philosophy of science and science education, Studies in Science Education, 12, pp. 25-57.

KLOPFER, L, 1976. A Structure for the affective domain in relation to Science education, Sci.Educ.,60(3), pp. 299-312.

MAGER, R., 1985. Desarrollo de actitudes ante la enseñanza. (Martínez Roca: Barcelona).

MARTÍNEZ AZNAR, M. M. et al., 1987. Enseñanza de las Ciencias, Vol, Extra, pp. 58-59.

MULDER, T. y VERDONK, A.H., 1984. J. Chem. Ed., 6, pp. $451-453$

NIENHOUSE, E. J. y NASH, E. G., 1971.J. Chem. Ed., 48, p. 141.

SCHIBECX, R. A., 1986. Images of science and scientists and science education, Sci. Educ., 70(2), pp. 139-150.

SEMINARIO PERMANENTE DE FÍSICA Y OUÍMICA "VEGAS ALTAS DEL GUADIANA», 1987. Método Activo de Química de COU, Enseñanza de las Ciencias, 5(3), pp. 225-230

SERRANO, T., 1986. La imagen de los científicos en los alumnos al finalizar el ciclo medio. Documentos IEPS, monografía núm. 1 .

SERRANO, T., 1988. Actitudes de los alumnos y aprendizaje de las Ciencias. Un estudio longitudinal, Investig. Escuela. 5, pp. 29-38.

SOLBES, J., 1989. Segundo curso de Formación de Formadores en Didáctica de las Ciencias. Valencia.

WETMORE, D.E. y MILLER, G. T., 1971.J.Chem. Ed., 48, p. 616.

YAGER, R. E. y PENICK, J. E., 1986. Perceptions of four age groups towards science classes, teachers and the value of science. Sci. $E d ., 70(4)$, pp. 355-364. 